\title{
CULTURA E POLÍTICA NOS ANOS 2010: ANSEIOS E IMPASSES NA OBRA DE ALINE VALEK E LADY SYBYLLA
}

Ana Rüsche (USP) Elton Luiz Aliandro Furlanetto (USP)

Recebidoem 25 jun 2018. Ana Rüsche é Doutora em Estudos Linguísticos e Aprovado em 27 ago 2018. Literários em Inglês na Faculdade de Filosofia, Letras e Ciências Humanas da Universidade de São Paulo FFLCH-USP; escritora, autora de "Do amor - o dia em que Rimbaud decidiu vender armas" (Novela, São Paulo: Quelônio, 2018) e "Furiosa" (Poesia, São Paulo: ed. autora, 2015); participa da Fantástika 451; pesquisa utopia, feminismo, ficção científica com interesse especial em Margaret Atwood e Ursula Le Guin. CV Lattes: http://lattes.cnpq. br/3640438371450743. Site: www.anarusche.com E-mail: anarusche@gmail.com.

Elton Furlanetto é Doutor em Estudos Linguísticos e Literários em Inglês na Faculdade de Filosofia, Letras e Ciências Humanas da Universidade de São Paulo FFLCH-USP; professor da Universidade Nove de Julho na área de Tradutor/Intérprete e Letras; foi bolsista da CAPES na University of Florida; pesquisa ficção científica, literatura norte-americana, crítica dialética, tradução literária e escrita criativa. CV Lattes: http://lattes.cnpq.br/4894694545222837. E-mail: elafurlanetto@gmail.com. 
Resumo: O romance As águas-vivas não sabem de si, de Aline Valek (2016), e a novela Deixe as estrelas falarem, de Lady Sybylla (2017), traduzem os anseios dos ideários culturais e políticos no Brasil contemporâneo. Neste artigo, discute-se o gênero literário "ficção científica", por intermédio do insólito ficcional, apresentando-se o contexto histórico nacional e internacional dos anos 2010. Nesse sentido, serão analisadas as formas literárias nos textos citados, tendo em vista a metodologia desenvolvida pela crítica materialista e observando-se as teorias feministas e os estudos de gênero no século XXI.

Palavras-chave: Ficção científica; Cultura; Feminismo; Sybylla; Valek.

Abstract: The novel As águas-vivas não sabem de si by Aline Valek (2016) and the novelette Deixe as estrelas falarem by Lady Sybylla (2017) reflect the cultural and political aspirations in Brazil today. In this paper, we discuss the literary genre "science fiction", through the ficcional insolitus, by presenting the national and international historical context of the 2010's and analyzing literary forms in both texts having in mind the methodology developed by the materialist critique and taking into account twenty-first century feminist theory and gender studies.

Keywords: Science Fiction; Culture; Feminism; Valek; Sybylla.

\section{A FICÇÃO CIENTÍFICA, A FANTASTIKA E O INSÓLITO FICCIONAL}

As narrativas, conforme indicado pelas áreas de estudo do texto, são produtos de uma subjetividade. Não obstante, estão sempre imersas em contextos discursivos sociais e coletivos. Tais contextos servem para estabelecer e definir os alinhamentos de quem escreve com a tradição, ou seja, o conjunto de escritos 
anteriores, formativos do artista, a que este recorre tanto para que reforçar ou reproduzir valores, estéticas, quanto para criticá-los ou negá-los. Todos os níveis da narrativa (personagens, foco narrativo, etc.) são manifestações desse alinhamento, porém a crítica tem se concentrado mais atentamente na categoria gênero literário.

O gênero, nos termos de Fredric Jameson, seria uma espécie de contrato social entre o escritor e um público específico, intencionando "especificar o uso apropriado de um determinado artefato cultural" (JAMESON, 1981, p.104). Trata-se, portanto, de um fenômeno por meio do qual podemos estabelecer protocolos de escrita e leitura. Os gêneros literários tendem a ser abertos e estão historicamente mediados, variando entre posições hegemônicas e residuais ou emergentes.

Em vista disso, um dos nossos primeiros passos seria indicar o gênero literário ao qual as narrativas selecionadas pertencem. À primeira vista, poderíamos afirmar que falaremos da ficção científica (FC). Porém, um dos poucos consensos que existe entre os críticos e teóricos da narrativa é a dificuldade em definir conceitos como a ficção científica. Adam Roberts (2018), em seu mais recente trabalho publicado no Brasil, A verdadeira história da ficção científica, inicia seu longo volume explicando as diferenças entre as possíveis definições de ficção científica.

Ele cita primeiramente o novum, criado por Darko Suvin, um elemento ficcional ou premissa que realiza uma dialética entre cognição e estranhamento, ou seja, entre aquilo que conhecemos e faz parte do nosso mundo e aquilo que faz parte apenas do mundo criado por quem escreve - como resume Roberts, trata- 
se de elemento que funciona tal qual um "dispositivo, artefato ou premissa ficcionais que põem em foco a diferença entre o mundo que o leitor habita e o mundo ficcional do texto de FC" (2018, p.37). O segundo teórico invocado por Roberts é Damien Broderick, para quem as mudanças epistêmicas - grandes mudanças culturais, científicas e tecnológicas - são a fundação do gênero, que passa a ser marcado por estratégias metafóricas e táticas metonímicas, além da atenção ao objeto preterindo-se o sujeito. Em seguida, Roberts cita Samuel Delany, o qual nos apresenta uma definição mais semiótica, indicando que "convenções codificadas" e "significados compartilhados" transformam a FC em uma estratégia de leitura. Como forma de demonstrar o longo e espinhoso debate sobre a definição do gênero, Roberts comenta que a Encyclopedia of Science Fiction traz dezesseis definições do que seja ficção científica.

Em nosso caso, toda essa discussão é relevante na medida em que grande parte dessas definições diferencia o realismo do fantástico. Mas o que seria esse fantástico?

Em uma releitura mais recente, o crítico norte-americano John Clute propõe o termo fantastika. Para ele,

Fantastika consiste em uma ampla gama de obras ficcionais cujos conteúdos são entendidos como fantásticos. Sabemos, é claro, que mitos e lendas, folclore e contos de fadas, fábulas com animais e jornadas fantásticas, novelas sobrenaturais e especulações utópicas, histórias de fantasmas e de deuses têm sido parte integral da longa narrativa da Civilização Ocidental desde o princípio: mas nenhum exemplo de qualquer uma dessas formas de histórias que antecedem o século XVIII ganhou, creio, um nome que as separasse da cultura mainstream. 


\section{$[\ldots]$}

Histórias começam a emergir e subverter a ordem [do Iluminismo]; contradizer a mundanidade estrita da obra produzida durante a Supremacia Apolínea; dizer que há mais no mundo que um adestramento na medida certa. Essas histórias re-importam todo material antigo, o irracional, o impossível, o pesadelo, o inevitável, o assombrado, o ficcionável, o cajado mágico, a maldição; e por meio dessas formas e estratégias renascidas, vemos, como estigmas aparecendo na porcelana, as vulgares partes baixas dionisíacas, os duplos reprimidos ou Doppelgänger que caçoam de Apolo e sua toga: assim é que a fantastika ela mesma macaqueia e caçoa e conta a verdadeira terrível sub-história do mundo que nós no ocidente entramos. (2007, s/p)

Clute ainda indica que, no século $X X I$, as três formas que a fantastika vai tomar são da ficção científica, fantasia e horror (que ele prefere chamar de terror). Esse conceito de Clute é muito parecido com o de ficção especulativa, usado nos anos 1990 e 2000 por diversos críticos, entre eles Roberto Causo (2003). Ambos os conceitos tentavam dar conta de abarcar os gêneros citados (e estavam circunscritos a eles). O esforço teórico de Clute não é indício de uma idiossincrasia intelectual, mas dá sinais da necessidade de se pensar categorias mais totalizantes, que deem conta de sistemas integrados, ainda que parcialmente autônomos, dentro da cultura. Porém, todas essas formulações apresentaram problemas conceituais e ainda não conseguiram transcender as definições dos gêneros que abarcam.

No Brasil, identifica-se uma nova orientação que tenta transcender os limites teóricos do fantástico, por meio do 
desenvolvimento de um conceito totalizante que dá conta de se contrapor ao realismo, sem se restringir aos gêneros citados.. Tratase do insólito ficcional.

Nas palavras de Matangrano e Tavares (2018, p.20), o conceito de insólito tem sido usado no Brasil como uma macrocategoria que pode dar conta dos mais variados "modos narrativos, estilos e temáticas". Entre eles, podemos citar a FC, o gótico, a fantasia, o sobrenatural, o realismo maravilhoso, o horror, o absurdo, etc. A sugestão do conceito veio de Flávio García, e se configura por "uma incoerência, incongruência, ou fratura de 'representação' - no sentido mais primário de mímesis - referencial da realidade vivida pelos seres de carne e osso em seu real cotidiano" (GARCÍA, 2014, Apud MATANGRANO e TAVARES, 2018, p.20). Seria, então, a oposição de dois sistemas narrativos: o real-naturalista e o não realnaturalista, ecoando a contraposição das visões de mundo apolínea e dionisíaca invocadas por Clute.

Podemos identificar nas duas obras escolhidas elementos do insólito mais associados ao progresso científico. O romance As águas-vivas não sabem de si, de Aline Valek (2016), e a novela Deixe as estrelas falarem, de Lady Sybylla (2017), poderiam ser classificadas como insólitas, considerando que a primeira faz uma incursão ao fundo do mar e a segunda ao espaço. Ambas, portanto, constroem narrativas em espaços alternativos àqueles já colonizados pelo ser humano. E o meio pelo qual as narrativas justificam a presença efetiva (e não apenas passageira) em tais locais é a ciência.

Dessa maneira, o termo ficção científica brasileira será utilizado neste artigo para descrever o gênero das obras analisadas, em 
respeito ao contrato social estabelecido entre quem escreve e quem lê, embora as obras possam pertencer igualmente à fantastika e ao insólito ficcional, construções teóricas válidas e interessantes.

Como veremos, as obras trazem algumas novidades no que diz respeito à incorporação de demandas políticas por representatividade no panorama de narrativas brasileiras, reflexo de momento histórico com o qual dialogam de maneiras diversas. Para entendermos esse diálogo, apresentaremos alguns elementos gerais da cultura e da política nos anos 2010 e elementos da narrativa que intentam incorporar ou rejeitar aspectos discursivoideológicos relevantes.

\section{CULTURA E MOVIMENTAÇÕES POLÍTICAS NOS ANOS 2010}

Início de século: panorama de crise global e movimentos anticapitalistas

Vivemos em um mundo tão integrado, no qual as operações cotidianas são tão interligadas, que qualquer interrupção - como a Síndrome Respiratória Aguda Severa (SARS), por exemplo provoca consequências que, em questão de dias, expandem-se a partir de fontes desconhecidas, na China, para transformar-se em fenômenos mundiais. (HOBSBAWM, 2013, p.152)

Conforme exemplifica Eric Hobsbawm, na primeira década do século XXI assiste-se ao acirramento dos efeitos da globalização, mantida a lógica cultural do capitalismo: um coronavírus que assole Beijing em uma noite chegará a Toronto e logo a muitas cidades ao redor do planeta. Assim também se passa com crises econômicas, fluxos de capitais e descontentamentos massivos, estando o Brasil imerso nesta matriz planetária. 
A década de 2010 no Brasil é marcada, então, pelos efeitos de uma das maiores crises cíclicas do capitalismo, o que trará reflexos na cultura política local.

A crise inicia-se no hemisfério norte a partir de 2008. Segundo David Harvey, "no epicentro do problema estava a montanha de títulos de hipoteca 'tóxicos' detidos pelos bancos ou comercializados por investidores incautos em todo o mundo", ressaltando que, no fim de 2008, "todos os segmentos da economia dos EUA estavam com problemas profundos" (2011, p.10). Na Europa, foi denominada como "Crise da dívida pública da Zona do Euro" e terminou por ser a maior crise econômica desde a Crise de 1929. Na União Europeia, foram feitos empréstimos financeiros a países com economias fragilizadas como Chipre, Espanha, Grécia, Irlanda e Portugal, desencadeando um "estado de aporia", como designa Yánis Varoufákis: um impasse, no qual certezas desmoronam diante da ausência de um modelo político e social que responda à magnitude da crise. Respostas governamentais europeias foram políticas públicas de austeridade severas, justificativas para desmantelar o que sobrou do estado de bem-estar social em acirramento de políticas neoliberais.

No Brasil, a crise internacional aportará em 2010. Mesmo com as tentativas de estímulo ao consumo do governo petista, a economia nacional, dependente de commodities agrícolas e minerais, não reagirá, gerando redução do crédito, desvalorização da moeda e aumento da desigualdade social. O ocaso da crise assiste-se agora, em 2018: exacerbamento neoliberal do governo Temer com cortes na seguridade social e em garantias trabalhistas históricas, medidas que não conseguem alterar a rota no aprofundamento da recessão. 
Se crises são "coronavírus globais" e afetam o Brasil, descontentamentos também o são: nos anos 10, influências globais de protestos anticapitalistas são sentidos em diferentes partes do país. Em 2010, com início na Tunísia, a Primavera Árabe deflagrou, no Oriente Médio e no Norte da África, protestos massivos que culminaram em deposições de governos no Egito, lêmen, Líbia, Tunísia, e conflitos sem soluções até hoje. Em 2010, o movimento estadunidense Occupy cunha a reivindicação "nós somos 99\%", em alusão à distribuição de renda global. Em 2011, o movimento 15-M, movimiento de los indignados, brada: "democracia real já, não somos mercadorias em mãos de políticos e banqueiros". Em 2012, no México ocorre o YoSoy132. Em 2013, por todo o território brasileiro, assiste-se às Jornadas de Junho ou Levante de Junho.

Rompendo o "estado de aporia", esses movimentos, por poucos meses, desafiaram a imobilidade da discussão do fazer político na década, com consequências marcantes para a cultura urbana global. Também receberão contramanifestações à altura de caráter discriminatório, nacionalistas, xenofóbicas, que culminam em fenômenos como a eleição de Trump, Brexit e votos para partidos de extrema-direita.

De maneira geral, os movimentos anticapitalistas citados foram organizados horizontalmente com práticas autonomistas, não se inserindo nem em programa político-partidário, nem sendo representados por instituições tradicionais, como sindicatos e partidos. O veículo digital é fundamental para propagação de ideias, imagens e mobilizações por amplos territórios urbanos. Em decorrência das estratégias, apresentam uma rapidez de aglutinação e também de desarticulação. De novidade, esses movimentos 
terminam por contagiar o Brasil com uma nova cultura política: são urbanos e de linguagem digital, possuem aguda percepção sobre privilégios de gênero e raça e colocam em suspeita a aquisição do conhecimento e o mérito de autoridades (RÜSCHE, 2015, p.22). Há um acento feminista nesses movimentos, apresentando, em alguns casos, protagonismo significativo de mulheres. Demandas históricas feministas, como horizontalidade e questionamento do que seja autoridade, são acolhidas no manejo de estratégias políticas de comunicação. O contexto histórico em que os textos em análise são produzidos reúne o acúmulo dessas discussões.

Compreender este contexto da década de 2010 é fundamental para se analisar as questões candentes que a novíssima literatura trará em suas páginas.

\section{ANSEIOS POR UMA CULTURA LITERÁRIA GLOBALIZADA E DEMOCRÁTICA}

Escritas no âmago da década de 2010, as obras em análise refletem seu momento histórico, anseios políticos e alterações culturais. As águas-vivas não sabem de si, de Aline Valek (2016), e Deixe as estrelas falarem, de Lady Sybylla (2017), reúnem características que exemplificam hoje a cultura e os anseios da produção literária da ficção insólita no Brasil.

As águas-vivas não sabem de si é um romance que se filia à tradição das viagens ao fundo do mar, ressaltando questões científicas sobre as afetações de corpo e mente nessa jornada. Em alguns capítulos, há construções de frase de caráter mais poético dialogando com o que se convenciona anodinamente denominar de "prosa literária" ou "romance contemporâneo" (obras de caráter 
realista, com uso de linguagem condensada e com candidaturas a um projeto de cânone nacional). A novela Deixe as estrelas falarem poderia ser descrita como uma space opera brasileira, com enredo de aventura e certo suspense, voltada ao entretenimento e de leitura rápida. Nesse primeiro momento, as obras apresentam uma contraproposta literária que parece não se vincular a instituições tradicionais como a academia e as críticas de segundos cadernos.

Mais significativas assim são as influências, especialmente de língua inglesa, de romances, filmes, séries e quadrinhos cita-se Becky Chambers, Star Trek, Star Wars, Ursula Le Guin e até mesmo o Discovery Channel, entre outras. Não registram preocupação em aludir explicitamente à literatura brasileira anterior, nem mesmo a obras de fantasia ou ficção científica de décadas predecessoras (para títulos a respeito, consultar CAUSO, 2013; GINWAY, 2014 e MATANGRANO e TAVARES, 2018). Preferem formar suas próprias redes de influência, sendo o veículo digital fundamental nessas aproximações.

Essa postura sugere aglutinar um sentimento-chave do contexto histórico: a aguda percepção sobre os próprios privilégios e a tentativa de democratizar o acesso à literatura. Tanto em termos de uso de linguagem quanto de referências, reconhece-se a existência de leitores de diferentes classes sociais, faixas etárias e origens, que estão dispensados de decifrar complexas citações artísticas canônicas ou estruturas de frase com inversões e léxico requintado. Em uma rara tradução de consciência de classe, esses livros procuram diálogo com pessoas sequer consideradas leitoras em outros tipos de produção. Em se tratando de Brasil, a postura também apresenta um impasse dialético, considerando, 
nas populações de baixa renda, as dificuldades de letramento, de encontrar tempo de lazer, de conseguir um alívio na renda para custear o preço do livro, entre outras.

Um desdobramento desse sentimento-chave pela democratização da literatura é a percepção mais horizontal entre quem lê e quem escreve. Apesar das trocas entre escritores e leitores sempre terem sido possíveis, nesta geração se oferecem a um tweet de distância: as duas autoras, Aline Valek e Lady Sybylla são pessoas que, sem dúvida, encampam diálogos com leitores por meio de redes sociais (Instagram, Facebook e Twitter, assim como em newsletters). Dessa maneira, termina por ser relevante para a recepção de seus livros a maneira pela qual escritores se manifestam em redes, discutem com leitores e compartilham o cotidiano.

Outro aspecto da época é a formação de bolhas ou nichos literários a partir da organização digital em redes. O estabelecimento da internet como principal ferramenta de comunicação social, incluindo uso massivo de redes e aplicativos, possibilitou a formação de nichos de consumo e bolhas de produção de literaturas especializadas. Por exemplo, uma pessoa que more em Maceió, Porto Alegre ou Ubatuba e que goste de fantasia, ficção científica ou terror terá, em 2018, mais facilidade de encontrar produtos e canais de comunicação que se amolde a seus gostos específicos do que poderia alcançar no século passado, quando dependia de catálogos impressos e indicações de profissionais do livro. Decorrências desse fenômeno são fomento a produções de gêneros literários especializados, maior exigência na complexidade das obras em termos de enredo, qualidade editorial e reunião de perfis políticos semelhantes, assim como circulação 
cruzada de informações sobre lançamentos e eventos em distintas partes do país.

Ainda é relevante considerar que a tarefa da crítica brasileira, antes reclusa a segundos cadernos em jornais de grande circulação, agora sofre mudança, sendo descentralizada em canais produzidos por leitores no YouTube ou mesmo em redes sociais como Goodreads (vide MATANGRANO e TAVARES, 2018, p.275-280). Embora tímida, marca-se ainda a presença do e-book no território nacional, bastante difundido entre quem lê ficção científica inclusive, Deixe as estrelas falarem, de Lady Sybylla, possui somente edição para leitores digitais, uma marca da editora Dame Blanche até o momento.

Essas alterações culturais com anseios democráticos em um país em crise econômica indissociável às flutuações globais terminam por serem literariamente absorvidas em camadas mais profundas nas obras em análise: nas escolhas temáticas, na criação de personagens e nas formas literárias utilizadas.

\section{DIÁlOgOS COM A FICÇÃO CIENTÍFICA BRASILEIRA}

Mesmo que as duas narrativas não façam referências explícitas às obras de ficção científica brasileira como antecessoras, se apontará sucintamente como as duas narrativas dialogam com essa tradição.

Embora as construções sobre antiguidade da ficção científica brasileira recuem ao século XIX, com obras como $O$ fim do mundo, de Joaquim Manuel de Macedo (1857), observa-se uma produção ininterrupta a partir do que se convencionou denominar "Primeira Onda" (1958-1972) ou "Geração GRD" - construção teórica iniciada em pesquisas de universidades nos EUA com estudos brasilianistas 
elaborados por Andrea Bell, David Lincoln Dunbar e Yolanda MolinaGavilán, levadas adiante depois, no Brasil, por Fabiana da Camara Gonçalves Pereira (2005, p.32) e Roberto Causo (2013, p.8), que adicionou os subsequentes "Ciclo ou Onda de Utopias e Distopias", de 1972 a 1982, e "Segunda Onda", de 1982 a 2004 (CAUSO, 2013, p.220-221). Partiremos do período da Redemocratização, quando a brasilianista M. Elizabeth "Libby" Ginway aponta uma consolidação do gênero, momento em que o Brasil "começa a construir seu próprio mundo da ficção científica nacional" (GINWAY, 2017).

No final de 1980, e durante a década de 1990, o mundo próprio da ficção científica nacional é firmado a partir de movimentações de antologias, clubes, fanzines e prêmios, como as fanzines Somnium e Megalon, que subsistem quase duas décadas. Em São Paulo, formase o Clube de Leitores de Ficção Científica ou CLFC. É estabelecido o prêmio Nova de ficção científica, oferecido de 1987 a 1996, juntamente com outro prêmio, o Argos. Fabiana Pereira irá resumir a temática do período que antecede a virada de século:

A problemática formal, a legitimidade desta produção em um país periférico e não produtor de tecnologia, ${ }^{1}$ assim como o caráter marginal do gênero em relação ao restante da literatura brasileira eram e são pontos principais neste debate. $(2005$, p.55)

Além desses temas, poderíamos ainda acrescentar um fascínio pelo universo cyberpunk, narrativas urbanas em que a cidade

1 Compreenda-se aqui referência à tecnologia estrita de caráter industrial de matriz ocidental. Frisa-se nosso entendimento de que o vocábulo tecnologia engloba um conjunto amplo de saberes e conhecimentos aplicados para a transformação de recursos naturais em produtos cotidianos que são inúmeros no território brasileiro e advêm de culturas africanas, asiáticas, indígenas, entre outras. 
se mostra um espaço do perigo, retomando características de ambientação do gênero noir estadunidense, e a máquina fundindose ao corpo. Roberto Causo (2013) denominará essa tendência de tupinipunk, anotando as diferenças de apropriação da proposta original de Bruce Sterling, John Shirley e William Gibson, entre outros autores norte-americanos.

No início do século XXI, essas tendências citadas por Fabiana Pereira são aprofundadas, incluindo uma preocupação historiográfica, usada como estratégia para reforçar a legitimidade da produção: serão feitas antologias que visam resgatar obras esquecidas pelo cânone realista. São exemplos Os melhores contos brasileiros de ficção científica (CAUSO, 2007) e Páginas do futuro (TAVARES, 2011), que recuperaram textos de Joaquim Manuel de Macedo, Machado de Assis, Raquel de Queiroz e Rubem Fonseca, afirmando-os como precursores de nomes atuais.

Analisando-se As águas-vivas não sabem de si, de Aline Valek (2016), e Deixe as estrelas falarem, de Lady Sybylla (2017), o maior contraste com gerações antecedentes é serem duas autoras, que incorporam nos temas das narrativas e posturas públicas a inserção de mais mulheres na produção dos textos.

No universo de antologias e revistas de ficção científica no Brasil até 2004, publicações que apontam indicações de leitura ou valorização de nomes, mulheres ocupariam um lugar absolutamente minoritário entre incluídos - pessoas negras são mais raras ainda entre as seleções realizadas. Para exemplificar, Roberto Causo, no artigo "Os Pulps Brasileiros e o Estatuto do Escritor de Ficção de Gênero no Brasil" (2014), trata de muitas revistas e antologias 
(como a Isaac Asimov Magazine, versão nacional da então Isaac Asimov Science Fiction Magazine dos anos de 1990), que raramente incluem mulheres nas seleções.

O panorama de desigualdade de gênero remete à conclusão da estatística de Regina Dalcastagnè, que, em sua análise, privilegiou o romance realista publicado por grandes casas editoriais entre 1990 a 2004 - a pesquisadora da UnB aponta: "Chama a atenção o fato de que os homens são quase três quartos dos autores publicados: 120 em 165, isto é, 72,7\%"2 (DALGASTAGNÈ, 2005, p.31). Na área da ficção científica brasileira, ainda carecemos de estatísticas e levantamentos precisos, embora o panorama provavelmente não seja muito distante do apontado por Dalgastagnè até 2004.

A partir de 2005, na Terceira Onda da Ficção Científica, designação de Roberto Causo (2014), ocorrerá mudança significativa de autoria na fiç̧ão científica brasileira, movimento corroborado pela participação das autoras das obras em análise. Ambas absorvem anseios feministas e posicionam-se politicamente. Chegaram, inclusive, a organizar dois números da antologia de contos Universo desconstruído: ficção científica feminista, com a chamada "por

2 Regina Dalgastagné explicita seus critérios com a seguinte formulação, excluindo em sua análise a ficção científica deliberadamente: "Assim, foi incluído na pesquisa todo romance que preenchesse simultaneamente quatro requisitos: (1) foi escrito originalmente em português, por autor brasileiro nato ou naturalizado; (2) foi publicado pela Companhia das Letras, Record ou Rocco; (3) teve sua primeira edição entre 1990 e 2004; (4) não estava rotulado como romance policial, ficção científica, literatura de autoajuda ou infanto-juvenil. A formulação dos critérios (2) e (3) implicava a possibilidade de incluir obras que tivessem saído em primeira edição por outras editoras, no período desejado, e depois sido reeditadas por uma das três casas editoriais escolhidas. De fato, ocorreram 14 casos assim, 5,4\% do total do corpus. O critério (4), por sua vez, excluía gêneros que são considerados menores e formam sub-campos próprios, às margens do campo literário". Acrescenta a nota de rodapé ao final da citação: "Estes gêneros são considerados menores pelo próprio campo, que lhes confere menor legitimidade e faz deles plataformas menos eficientes para a busca da consagração literária" (DALGASTAGNÈ, 2005, p.24). 
uma ficção científica que não seja machista, homofóbica, racista" (SYBYLLA e VALEK, 2013 e 2015) com distribuição gratuita digital, somente custeados na opção impressa.

Em preocupações que se assemelham às gerações anteriores, ambas as escritoras tematizam o que seja viver em um país periférico e não produtor de tecnologia industrial. Em As águasvivas não sabem de si está claro que a protagonista é mera usuária da tecnologia produzida pela indústria de trajes, sendo sua profissão testar equipamentos previamente desenhados. Em Deixe as estrelas falarem, a protagonista, para se tornar capitã, precisa reformar a própria nave, um cargueiro avariado cujos motores ela regenera, faz melhorias na gravidade artificial e, inclusive, na pintura - uma atitude que se reconhece em locais mais distantes da produção tecnológica computacional ou automobilística, quando pessoas montam e reformam equipamentos a partir de peças usadas, conhecimentos valorizados como positivos na novela de Sybylla.

Por fim, anota-se que não se verifica, na descrição ou ambientação, o toque noir ou tributos ao cyberpunk, bastante populares até o presente momento na produção nacional.

\section{DUAS NARRATIVAS E SUAS REIVINDICAÇÕES}

De saída, seria possível afirmar que as duas narrativas inovam por movimentarem materiais de conteúdo sociocultural não sedimentado na literatura brasileira e em bastante sintonia com as questões candentes no atual momento histórico.

Os dois livros sublinham discursos comuns a movimentos anticapitalistas mencionados. Demandas políticas como o reconhecimento do racismo e a necessidade de combatê-lo; 
discursos a respeito de gênero, como feministas e LGBTQ, assim como a discussão sobre o que seja autoridade e a instituição do poder conformam as obras, sem esquecer que as discutem a partir de experiências de vida tipicamente latino-americanas.

Da mesma forma que essas demandas políticas conformam as narrativas, diante do cenário de crise cíclica e da não superação das contradições capitalistas e diante ainda das oligarquias brasileiras que perpetuam as injustiças sociais no país, os anseios utópicos capitulam em impasses. A análise tratará de observar essas oscilações utópicas e distópicas na formação das duas narrativas.

Como já dito, com relação a características gerais, o romance As águas-vivas não sabem de si, de Aline Valek (2016), e a novela Deixe as estrelas falarem, de Lady Sybylla (2017), realizam deslocamentos, a primeira com uma incursão ao fundo do mar e a segunda ao espaço. Por serem espaços não ocupados pelos seres humanos na realidade empírica, temos a presença do insólito ficcional. Ambas as obras apresentam protagonistas mulheres e se organizam em torno de longas jornadas.

Não deixa de ser interessante às questões feministas o fato de o espaço privilegiado nas duas narrativas ser um ambiente fechado: as obras são investigações sobre instituições totais - tripulação de uma nave espacial e de uma estação submersa - que terminam por apresentar regras próprias de conduta e interação. O sociólogo Erving Goffman (1974, p.11) define instituições totais, ao tratar de manicômios, prisões e conventos, como "um local de residência e trabalho onde um grande número de indivíduos com situação semelhante, separados da sociedade mais ampla por considerável 
período de tempo, levam uma vida fechada e formalmente administrada". Segundo Goffman, em instituições totais, há constante tensão entre o mundo doméstico e o mundo institucional. Aponta-se aqui um dispositivo efetivo: as autoras, ao analisarem a interação de pessoas em uma nave ou estação submersa nada mais fazem do que tematizar literariamente sobre uma questão cara às lutas das mulheres, a interação entre o ambiente privado e do público. Situando as narrativas em ambientes que perfazem esse duplo entre mundo doméstico e institucional, logram discutir as duas facetas de forma simultânea.

Destaca-se a agência de certa linha que poderia ser referida como "feminismo intersecional". De matriz estadunidense, inicialmente denominado de "feminismo da diferença" (ÁVILA e COSTA, 2005), ele irá marcar a década de 1990. O nome inicial alude à influência da différence francesa - esta linha teórica problematizaria a estrutura binária de gênero. Quando é depois denominada de "abordagem interseccional", exige-se que o termo "feminismo" sempre inclua demandas de mulheres latinas, negras, asiáticas, indígenas assim como pessoas trans, uma tentativa de coibir a contaminação do feminismo liberal de mulheres cis brancas de classe média dos Estados Unidos, embora esta linha interseccional não se apresente necessariamente anticapitalista.

A respeito de feminismo e movimentos anticapitalistas, é interessante lembrar das ideias de Nancy Fraser (2009, p.28). Em épocas de nova ascensão do neoliberalismo, em que se assiste ao desmonte do estado de bem-estar social, privatizações, cortes de garantias trabalhistas e previdenciárias, muitas das demandas que foram construídas pelo movimento feminista até então - como 
autonomia, horizontalidade e diminuição da autoridade - são reincorporadas às práticas neoliberais intensificando a valorização do trabalho assalariado (RÜSCHE, 2015, p.77). Arranjos que Trebor Scholz denomina de "ubercapitalistas" ou "ultraneoliberais" - popularizadas pelo uso do aplicativo Uber - terminam por ser flexibilizações festejadas por quem trabalha a partir de um ideal de liberdade ("não tenho mais chefe"), embora, na prática, o ideal não se concretiza, tendo que o trabalhador entrar com seu carro e seu celular, além da sua velha força de trabalho, para conseguir remuneração de uma plataforma digital, a qual o submete a avaliações e cortes sem maiores explicações (SCHOLZ, 2016, p.28-32). Em resumo, o ponto-chave de afinidade dos dois programas - feminista e neoliberal - encontrarse-ia na crítica à autoridade tradicional. No feminista, sair da sujeição masculina. No neoliberal, retirar obstáculos à expansão capitalista.

Vejamos como as narrativas incorporam anseios políticos do feminismo interseccional em suas páginas, assim como as exigências por relações mais horizontais, menos hierárquicas, embora não se livrem do fantasma de uma crise cíclica capitalista, impasse no qual atuam forças históricas que conformam o Brasil na contemporaneidade.

\section{AS ÁGUAS-VIVAS NÃO SABEM DE SI: PROCURAR SENTIDO É SE LANÇAR AO ABISMO}

Publicado em 2016, o romance de Aline Valek trata da estação submarina Auris e seu cotidiano, intercalando descrições sobre a vida marinha e suposições sobre vida alienígena na Terra. Diante da protagonista Corina, perpassam as páginas o tema da solidão, do sentido da vida e mesmo a importância da preservação ecológica. 
As águas-vivas não sabem de si apresenta, para conformar sua narrativa, o artifício-base da descontinuidade de gêneros - uso de tons, construção de narrador, linguagem, espaço diferente a cada um ou dois capítulos do livro, como se pertencessem a outra narrativa, contrapostos em colagem (JAMESON, 2005, p.254-258). A alternância de dois gêneros foi utilizada para se amarrar diferentes materiais literários: o discurso filosófico com linguagem de maior densidade poética sobre espécies não humanas e a narrativa dos percalços da vida dentro da estação submarina Auris.

Seguem dois excertos exemplificativos dessa alternância de tratamento entre temas existenciais a respeito da vida no fundo do mar e de narração tendo em vista a perspectiva da narradora Corina:

Excerto 1: Águas-vivas cor de carne bailavam, rodopiantes, flutuando num espetáculo com uma plateia numerosa, porém totalmente indiferente, mais interessada na própria marcha rumo à multiplicação. Essa era, afinal, a dança que aquelas bactérias entendiam como primordial, a verdadeira arte, algo tão grandioso que diante dela as gigantes não passavam de cenário. Figurantes.

$\mathrm{Na}$ escala das pequenas dimensões, outros braços continuavam a dança. Na ânsia de tocar algo além do vazio, cerdas de um verme marinho dedilhavam as águas. Movimentos tão minúsculos quanto imensos em voracidade - a fome, a urgência, o agora... isso era tudo o que podia existir - na tentativa de agarrar algum krill que inadvertidamente encontraria ali o destino final de sua viagem.

$\mathrm{Na}$ boca aberta e flácida de um peixe gelatinoso: foi onde a viagem terminou para um pequeno camarão transparente que cuidava dos próprios 
assuntos, e ele passou por aquela garganta sem protestar, mais por falta de chance do que por uma compreensão profunda de que esse era mesmo o seu papel. O peixe, agora alimentado, seguiu serpenteando sua longa cauda pelas profundezas, alheio ao fato de que, lá em cima, havia quem considerasse inabitado o mundo onde ele vivia. Ao redor, um cenário muito quieto - mas não morto. Atento. (VALEK, 2016, posição 38-43 - daqui em diante será citada apenas a posição nas citações dessa obra).

Excerto 2: Corina olhou para ele durante um segundo, sobrancelhas tensas sobre os olhos, pensando em perguntar "o que você quer dizer com isso?", pensando o quanto ele podia saber, pensando em responder algo que pudesse disfarçar seu desconforto; em vez disso, apenas respirou alto e foi em direção à passagem que dizia "saída". (posição 179).

A configuração de personagens obedece ao espírito dos tempos e será uma constante na análise também da obra de Lady Sybylla, trazendo uma diversidade de gênero e raça que marca essa produção condizente a um feminismo interseccional: além de uma mulher protagonizar a narrativa, a mergulhadora Corina Costa, a engenharia da estação fica a cargo de outra mulher, Susana. 0 principal parceiro de trabalho de Corina é Arraia, um homem de pele parda. Dr. Martin S. Davenport é um cientista negro estadunidense que coordena as atividades e trabalha com o oceanógrafo Maurício, o qual sofre com boatos sobre sua homossexualidade.

A inclusão de diversidade traz tensões à narrativa com questões próprias. Corina tem suas capacidades questionadas por colegas homens em duas vezes, primeiro pelo Dr. Davenport, que não julga 
crível que a mergulhadora possa ter lido um livro de divulgação científica e, em segundo, pelo próprio parceiro de trabalho, Arraia, que a julga alterada - "estava exausta de ser incompreendida pelos outros, de ser vista como alguém sempre difícil de alcançar, quase como alguém que fosse irreal demais para existir. 'Eu não entendo você', Corina escutou tantas vezes, mas era ela que não entendia como podia ser uma pessoa tão difícil" (posição 1745); e em outro trecho, “'Eu não entendo você', disse ele, e ouvir aquilo não era nenhuma novidade para Corina" (posição 1835).

A engenheira Susana não consegue acreditar no próprio trabalho, sugerindo-se que sofra de "síndrome da impostora", sem acreditar nas próprias potencialidades, embora sua trajetória como engenheira seja marcada diversas vezes pelo machismo do meio:

\footnotetext{
"Vocês não me levam a sério mesmo, né?" Susana soltou os braços ao lado do corpo, em um gesto de cansaço que estava ali havia muito tempo, desde antes de Auris, desde antes de seus outros trabalhos, talvez um cansaço que vinha desde os tempos de faculdade, dos olhares de zombaria, de perguntarem "você, engenheira?" e ela se armando cada vez mais com aquela pose séria para não deixar que a desacreditassem outra vez. (posição 1805)
}

As outras pessoas confinadas na estação Auris também foram atacadas por preconceitos: Davenport teria sido desacreditado no ambiente acadêmico, assim como Maurício perseguido por boatos. Seriam as causas racismo e homofobia, respectivamente? Ao inserir personagens com maior pluralidade, a narrativa ganha em densidade e em debates sociais, além de dialogar com anseios políticos da década. 
Essa reunião de pessoas está confinada na estação submarina Auris a trezentos metros de profundidade com a seguinte missão: testar os Trajes Especiais para Mergulho em Profundidade Abissal TEMPA 269, armadura experimental de 65kg.

Dr. Davenport possui outro plano científico e, enquanto Arraia e Corina testam trajes, o cientista procura se conectar com criaturas oceânicas, em busca do contato com outras espécies inteligentes ("Estamos a dois passos de descobrir uma nova espécie, muito provavelmente tão inteligente quanto qualquer um nesta sala, vivendo em algum lugar deste oceano" (posição 1795). Em narrativa em separado, sabe-se que os azúlis são as tais criaturas inteligentes que permaneceram nas profundezas abissais e provavelmente alienígenas: "os azúlis desenvolveram corpos graciosos, de forma gelatinosa, quase totalmente translúcidos e dotados de uma luminescência azul que era marcante em um lugar tão escuro e frio quanto o fundo do abismo" (posição 1588). Essa configuração física dos azúlis desafia a primazia humanoide da imaginação no Antropoceno, época atual do planeta em que ações humanas alteram significativamente o clima e ecossistemas.

A vida na estação Auris gira em torno do trabalho. Mesmo diante da maravilha de segredos oceânicos e cânticos de baleias, é interessante, porém, observar que não se sabe muito bem quem são os verdadeiros empreendedores da missão, ou seja, não se acrescentam detalhes a respeito dos donos dos trajes TEMPA. Arraia e Corina, mergulhadores de país em desenvolvimento, não passam de cobaias ao experimento:

Confiança era algo perigoso para carregar àquela profundidade. Confiança demais em equipamentos, 
cálculos e pessoas das quais se sabia pouco mais do que os dois primeiros nomes e a formação; mas, sem confiança, melhor que tivessem ficado em empregos seguros em vez de assumir um trabalho que consistia justamente em ser cobaia para comprovar que algo era seguro. Portanto, confiar em quem? Em quê? Confiança, naquele ponto, confundia-se com loucura. Lançar-se na escuridão sem nenhuma garantia de descobrir o que quer que fosse - ou de voltarem vivos, pelo menos - só poderia ser definido como a mais insana das posturas diante de uma vida ridiculamente frágil e curta. No entanto, Corina não deixou de reparar na estranheza da situação, apesar de tudo, em estarem ali aprontando os equipamentos, apertando botões e metendo braços e pernas num aparato de metal como se muito racionais, e calma que temos toda a situação sob controle. (posição 514-517 - grifos da autora)

Os empreendedores, fabricantes dos trajes TEMPA 269, à semelhança do $1 \%$ da população contra qual se insurgiram protestos do Occupy Wall Street ou mesmo à semelhança de donos de plataformas de aplicativos como o Uber, nunca possuem rosto ou mesmo envolvimento pelas vidas em jogo na estação submarina Auris, uma mão invisível que detém a produção de mercadorias, muitas vezes exploradora, irresponsável e irracional.

A narrativa mantém Corina amarrada em sua condição social de trabalhadora latina. Sem conseguir superar dilemas da mergulhadora brasileira cujo corpo não passa de campo de provas para um experimento, a narrativa capitula. Mesmo que tenha sua individualidade valorizada pela narrativa e termine tomando as rédeas da própria história até se insurgir contra as regras da estação 
Auris e contra as ordens de Davenport. Sua teimosia e curiosidade lançam Corina em uma missão suicida em busca de conhecimento, em um último mergulho, quase como se fosse por distração, por acaso, sem perceber, afirmando sua escolha: "Dentro do traje, eu esperei por esse dia" (posição 3028).

Corina não encontrará nenhum azúli, mas entrará em contato tênue com uma outra criatura, um espectro ("um fantasma pairando sobre cadáveres de corais, náutilos, peixes acantódios, derramando sobre eles um pouco de sua própria luz.", posição 1927). Na narrativa paralela, saberemos que um espectro presenciou o momento trágico de extinção dos azúlis e guardará a canção em seu corpo que vibra:

Foi assim que [o espectro] captou uma presença no interior daquelas ruínas. Moveu-se com cautela para mais perto, onde sentiu tentáculos e um corpo mole, muito parado, mas ainda vivo. Se tivesse qualquer lapso de consciência, talvez o espectro tivesse se entristecido com o que testemunhou quando se deparou com um dos últimos azúlis, sozinho, vagando pela cidade fantasma. Não tinha, no entanto, a capacidade de saber o que era tristeza ou mesmo de empatizar com a angústia expressa pelos movimentos do azúli [...]

O espectro percebeu que seu corpo conseguia vibrar de forma parecida e imitou aquele som algumas vezes antes de encontrar o próprio fim, afundando sem vida para bem longe dali. (posição 1946 a 1954)

A mergulhadora faz um contato tênue com o espectro, então, os dois seres se separam. Corina o segue afundando no abismo abissal, quando insiste em perder contato com Auris e o resto da 
equipe, consciente do perigo à vida que o derradeiro mergulho representaria: "Curiosidade. Teimosia. Loucura." (posição 2902). O oceano a acolhe em sua libertação. "Um traje vazio afundando devagar no escuro. Um acidente, mais um pedaço de lixo enviado pela superfície, uma oferenda. Uma coisa sem significado, uma mensagem pela metade, uma resposta, uma tentativa de contato." (posição 2961).

O final da narrativa lança uma luz interpretativa que ilumina todo o romance: Corina iria realizar o inédito e tão aguardado contato com a mensagem proveniente de outra vida inteligente no planeta, entretanto, o faz por meio de uma mensagem copiada, desgastada, que vibra no corpo do espectro e então se lança ao abismo em direção à morte: "Aquele tipo de criatura mais fina que papel carregava o único vestígio do que um dia foi uma civilização, e era um registro tão quebradiço quanto tudo mais que um podia morrer". (posição 2869).

A narrativa constrói uma relação de alteridade, na qual o Outro é uma entidade frágil, monádica. Não apenas o objeto dessa relação é fragilizado, o encontro em si se faz por meio de cópia espectral, sem aura da tragédia da extinção dos azúlis, choque materializado pela efemeridade, precariedade e destruição.

A exemplo das discussões entre Joanna Russ e Darko Suvin, consolidadas por Tom Moylan em Distopia: fragmentos de um céu límpido (2016), segundo Suvin, se o "final é o momento da verdade para a validação do novum cognitivo e para a verossimilhança da narrativa" (considerando este novum aquilo que excederia os limites sociais e formais do presente, sendo no romance o primeiro contato 
entre humanidade e alienígenas), e, segundo o acréscimo feminista de Russ, se mitos literários "seriam a encarnação dramática do que uma cultura acredita ser verdade - ou acredita que poderia ser verdade - ou teme mortalmente que talvez possa ser verdade" (RUSS, 1995, p.81), o impasse no encontro entre Corina e o espectro aponta para uma incapacidade imaginativa que permeia um inconsciente político: ainda não se vislumbram, no Brasil de hoje, saídas para que se desenhe o arco dramático com final triunfante, um outro final que não seja a libertação pela morte.

Aparentemente, diante da ausência de solução no horizonte imaginativo, a única resposta ao se procurar um sentido para a vida e o contato com algo maior foi se lançar ao abismo.

\section{DEIXE AS ESTRELAS FALAREM: A GENTE FIEL E TRABALHADORA}

Deixe as estrelas falarem é uma novela de Lady Sybylla que narra as viagens interplanetárias da capitã Rosa Okonedo a bordo do cargueiro independente BCS Amaterasu. O livro sugere que ainda haverá continuações com edições de novas aventuras da capitã, em um movimento clássico de outras séries do gênero, como Jornada nas Estrelas (Star Trek). A obra traz uma diversidade significativa na escolha de suas personagens dentro de uma ideia de feminismo interseccional, a começar com a própria protagonista, uma mulher de 90 anos (embora aparente menos com a tecnologia de sua era); há personagens como Akilah, técnica de comunicação, com "cabelos raspados, pele escura e lábios em forma de coração", cuja beleza é elogiada; monogamia não é regra e, no universo retratado, as mulheres possuem muito maior igualdade do que no atual século XXI. 
Narrado em primeira pessoa, apresenta o universo da capitã em seu cotidiano e dificuldades em manter seu propósito ético, pagar a tripulação, lidar com propostas suspeitas de transporte e cargas misteriosas.

No espaço há quase 40 anos, Rosa Okonedo é o retrato de uma mulher batalhadora, orgulhosa da profissão: "abandonei a vida colonial, a vida de funcionária do espaço-porto, minha primeira esposa e uma relação disfuncional, apostei alto e ganhei o cargueiro de casco desgastado que parecia não querer mais voar" (SYBYLLA, 2017, posição 299).

O retrato é de uma mulher que trabalhou duro por décadas para ter a propriedade de um cargueiro: "uma belezinha. Era a nave mais bonita da frota independente e era minha" (posição 127). Proprietária do cargueiro que ela reformou, "minha primeira carga foram dois contêineres de tangerinas que implorei a um conhecido para poder carregar até o planeta vizinho, porque precisava do dinheiro, já grávida de Maísa" (posição 303). Com raciocínio empreendedor e energia da "desbravadora que não aguenta ficar parada" (posição 71), reuniu uma tripulação escolhida a dedo, "eu tinha gente fiel e trabalhadora" (posição 265).

A personagem reúne em si as tensões da classe trabalhadora brasileira, as contradições em administrar um negócio frágil diante de megacorporações sem conseguir superar a lógica capitalista e os impasses da cultura colonial brasileira.

De um lado, Okonedo mostra-se diligente em resguardar os direitos de sua tripulação e quer sempre ser uma boa capitã. Diante da oferta de uma carga ilegal, necessária para seguir adiante com 
os negócios, consola-se, "a visão dos meus tripulantes sem dinheiro apertou meu coração" (posição 510), e raciocina "se eu conseguisse um bom fundo de reserva, podia dar um bônus a todos eles pela dedicação e deixar vários meses de manutenção pagos".

Por outro lado, toma decisões unilaterais, colocando a tripulação em situações sensíveis - para exemplificar, no mesmo episódio em que aceita transportar a carga ilegal, o faz sem consultar antes os trabalhadores se aceitariam o perigo: "Eles [a tripulação] não chiariam por ser algo ilegal. Acho." (posição 526). Delineia então um plano para evitar amotinados, "vou esperar todo mundo vir a bordo, saímos de Vishnu e aí eu falo qual é o plano" (posição 548). No momento em que anuncia a carga ilegal a bordo, declara para todos os trabalhadores: "Quem quiser ficar em Vishnu ainda tem tempo" (posição 569).

Como a narração é feita na primeira pessoa da empreendedora, não é possível entender qual a dimensão do problema pela perspectiva dos trabalhadores - seria possível pedir demissão e abandonar o cargueiro, permanecendo em um porto espacial sem emprego? A oscilação entre ser uma boa patroa e sobreviver na lógica cruel de transporte espacial de cargas termina por aludir a uma cultura que se conhece bem: a velha cultura do compadrio senhorial brasileira, o que é reforçado pelo fato de a capitã, a todo o momento, demonstrar profundo envolvimento emocional nas relações que seriam, a princípio, de trabalho.

A lógica capitalista ainda guarda outros traços familiares à cultura na América Latina: a necessidade, diante da falta de outros meios para se ganhar a vida, de assumir a ilegalidade como razoável. 
Mesmo tendo passado dois anos presa na detenção de Mafeteng por crime de contrabando, a capitã não possui escolhas possíveis para resguardar sua tripulação e aceita os riscos de transportar um único contêiner misterioso por um valor exorbitante de que necessita para seguir navegando.

A novela, assim, é das mais interessantes como retrato de relações insuperáveis na lógica do sistema neoliberal dentro de uma perspectiva latino-americana. Mesmo que extrapole e traga anseios feministas materializados em um futuro, a representação do ambiente comercial, no qual a sobrevivência de um cargueiro independente segue frágil diante de megaconglomerados, é mais do que condizente ao momento de crise cíclica capitalista no qual o Brasil está imerso.

Em relação aos gêneros que conformam a novela, embora apresente a roupagem da space opera, a obra estrutura seu conflito de maneira semelhante a romances voltados a mulheres - são exemplos de conflitos: (a) o drama de deixar para trás filha e neta recém-nascida para capitanear o cargueiro, (b) manter sua posição de comando e (c) lidar com o envelhecimento, conforme se pode exemplificar em três excertos:

Excerto a: Ver sua filha chorar de tristeza racha seu coração, por mais duro que ele seja. (posição 83)

Excerto b: Eu sou a capitã Rosa Okonedo, do cargueiro BCS Amaterasu, número de registro 0972-4460. Um cargueiro comercial tripulado entre tantos outros, o mais velho em operação com a mesma capitã, o que mais transportou farelos de milho e soja em toneladas, premiado três vezes por excelência em serviço pela autoridade de comércio. Ele estava lá em cima, ancorado no estaleiro de 
Escorpião, na outra ponta do elevador espacial, e eu não me aguentava de saudade de seus corredores e passadiços, do suave ronronar do motor ressonando por todo casco, da minha querida tripulação. Estou indo para casa. (posição 102)

Excerto c: Com a idade que eu tinha e com o tempo de estrada, não era incomum ver tantos colegas deixando o ramo. Não deixava de ser triste, sabe? Não dava para evitar a sensação de estar sendo ultrapassada. (posição 289)

Conforme mencionado, a novela se passa em uma era futurística de reconhecimento total do direito de mulheres, inclusive relações não monogâmicas no melhor espírito do feminismo do século XXI. Assim, é interessante analisar, neste texto específico, a fricção, no plano das formas literárias, entre um conteúdo literário de "espírito genuinamente feminista interseccional" e a força da tradição literária do romance para mulheres.

Se, de um lado, a novela possui um conteúdo vanguardista, assumindo uma era em que há equiparação entre gêneros, por outro lado, quando literariamente o institui, utiliza formas literárias da tradição de romances escritos para educação sentimental do público feminino, com ênfase em conflitos interpessoais e temáticas como a responsabilidade perante a família.

Não há capitulação, entretanto, neste movimento. Assim como o "tornar-se mulher" depende de um processo histórico e psicológico de reconhecimento de diferenças e especificidades longamente em debate e que, até o presente momento, segue candente, uma utopia da literatura além-gênero ainda está por ser imaginada. O impasse é fruto dos tempos e Deixe as estrelas falarem faz parte dessa roda criativa. 


\section{O FECHAMENTO NAS DUAS NARRATIVAS}

Em outro momento (FURLANETTO, 2010), já discutimos a relevância das análises acerca dos fechamentos das narrativas. Ilustramos o argumento com a explicação de Jameson (2005):

para que a narrativa projete algum senso de uma totalidade de experiência no espaço e no tempo, ela deve certamente conhecer algum fechamento (uma narrativa deve ter um final, mesmo que ela esteja engenhosamente organizada na intenção da repressão estrutural de um final como tal). Ao mesmo tempo, entretanto, o fechamento ou o final da narrativa é a marca do limite ou fronteira além do qual o pensamento não pode ir. 0 mérito da ficção científica é dramatizar essa contradição no nível do enredo, já que a visão da história futura não pode conhecer nenhum final pontual desse tipo, ao mesmo tempo em que sua expressão como romance exige algum final. (p.273, tradução nossa)

Um dos elementos do insólito seria a possibilidade de narrar por meio de gerações ou com um deslocamento temporal da narrativa que transcendesse o tempo de vida de um personagem protagonista (exceto quando seu tempo de vida pode ser prolongado por algum meio externo). Porém, as narrativas organizam suas conclusões no momento final de Corina e na reflexão de Rosa sobre suas atitudes no que diz respeito ao acontecido durante o enredo. Tais fechamentos estruturais da narrativa dão sinal dos fechamentos ideológicos e simbólicos a que nos referimos anteriormente.

No caso de Valek, temos a escolha de Corina. "Sua existência humana era, afinal, uma jornada que tinha prazo para acabar, e o seu corpo era um traje não muito confiável que lhe deram 
para encarar essa viagem. Dava para ir mais fundo, por que não deixavam?" (posição 2913). Ao desacoplar o cabo, que se compara a um cordão umbilical, Corina dá início a um processo de autodestruição, motivado pelo desejo de se livrar das suas amarras terrenas. Se a cena descrita fosse a conclusão do romance, uma das possíveis interpretações seria que a única maneira de se lidar com todas as formas de constrição social seria a autodestruição. Muitas narrativas contemporâneas enfatizam esse ponto, mas normalmente o fazem a partir de uma posição de perigo explícito (e mostram tal destruição como um ato de heroísmo).

A escolha pela autodestruição revela uma incapacidade da personagem de se ligar com seus semelhantes, uma vez que seu Outro mais alterno, o espectro que vibraria uma mensagem azúli, seria mais sedutor que toda sua realidade. A prova da existência do ser marinho não fazia com que um esforço coletivo, um processo novo de tentativas mais preparadas para as novas condições se materializasse. Ao contrário, o sonho pareceu mais real para a personagem, e o abismo, que assustava os outros, como Dr. Martin Davenport, foi seu destino e sua libertação.

Após esse capítulo, o foco narrativo se inverte. A cena do sacrifício de Corina é observada do ponto de vista do oceano, que ora é si mesmo, ora é Corina. Os dois se fundem, fisicamente, enquanto a água invade o traje e a pressão diminui mais ainda o corpo da personagem. Ao que parece, esse capítulo serve como um aspecto compensatório da descrição da cena final. Parece que apenas abandonar Corina em seu ato final seria complicador demais, precisa-se de uma forma de suavizar sua solidão extrema, seu desajuste dentro do tipo de arranjo social em que está inserida. 
Cria-se, portanto, essa fuga das condições sociais e, ao simular um amálgama entre animado com inanimado, a autora expressa a contradição latente no seu momento histórico, no qual a fuga individual sobrepuja qualquer outro tipo de solução coletiva.

Um processo similar, ainda que em grau diferente, acontece no livro de Sybylla.

Podia uma estivadora como eu ter tantos pensamentos filosóficos e morais quando era possível apenas dar de ombros e pegar o próximo trabalho?

- Não sei dizer, Mike.

- Se o que você carregava era mesmo um alienígena, todas as experiências que você e sua tripulação tiveram podem mesmo ter acontecido. Eles são telepatas, empáticos e podem manipular pensamentos e sonhos.

- Me preocupa mais saber que eles estão sendo usados como experimentos ao invés de serem respeitados pelo o que são. Deixados em paz como pediram.

$[\ldots]$

- Muito estrago já foi feito. Esqueça o assunto, Rosa. É melhor assim.

- Não vou falar mais sobre o assunto, mas esquecer... - o observei com cuidado. - Aliás, pra quem eu vou contar? Quem vai acreditar em mim? São só histórias de uma capitã que passou tempo demais no espaço, é o que dirão. (posição 1223-1239)

No começo desse excerto, percebemos que a narradora interrompe um processo de reflexão a respeito da moralidade da 
sua escolha, como forma de compreender as vicissitudes sociais, e prefere se ater a uma proposta mais individualizada, uma renúncia à reflexão e uma reorientação ao trabalho.

O diálogo que ela estabelece com Mike Puatai tende a realizar um movimento de tensão e relaxamento. A preocupação ética da personagem se sustenta na sua fala, ao passo que o exmarido funciona como uma espécie de id freudiano, sugerindo o apagamento da memória e reforçando que não deve haver nenhum tipo de culpa por parte da personagem, nem mesmo uma tentativa de esclarecimento e aprendizado coletivo.

A fala final não adere ao argumento do esquecimento, porém reconhece a impossibilidade de a sua sociedade permitir a discussão e a reflexão sobre o Outro. O que se imagina é que outras situações similares àquela experimentada por Rosa podem se repetir, e essa repetição se dará pela forma como o sistema social está organizado. Não existe, no horizonte da narrativa, nenhuma maneira de se lidar social e positivamente com a alteridade e, ao encerrar a narrativa com essa mensagem, Sybylla também parece invocar as impossibilidades de pensamento social da geração dos 2010 . O futuro é tão individualizado e pouco reflexivo como o presente.

Desse modo, focamos nossa atenção para o fechamento dos dois textos porque são elementos das narrativas determinantes para entendermos o alinhamento político das escritoras. Tom Moylan (2016) indica, a partir de outros estudiosos, como o final aberto (open-ended) e o final fechado (close-ended) registram um tipo de estrutura de sentimento, indicando ora um movimento para "um pessimismo honesto, no lugar de um otimismo idealista". 
Nos termos do crítico (2016, p,59), duas alternativas estão disponíveis: "o 'pessimismo resignado', que se recusa a considerar as possibilidades latentes existentes do período histórico, e um 'pessimismo militante'", o qual dá à humanidade o poder e a coloca na linha de frente do processo histórico.

No caso das nossas narrativas, percebemos o apagamento dos modos de exercitar questões políticas e a inabilidade de exercitar o potencial disponibilizado pelo feminismo e pelas tradições contracapitalistas. Entretanto, indicam caminhos que podem ser explorados por pessoas que irão escrever e ler em um futuro próximo, que podem se apropriar do "pessimismo resignado" e dar novos passos em direção a um futuro mais justo, equilibrado e militante.

\section{REFERÊNCIAS}

ÁVILA, Eliana; COSTA, Claudia de Lima (2005). "Gloria Anzaldúa, a consciência mestiça e o 'feminismo da diferença'". Revista Estudos Feministas. Florianópolis, 13(3), set.-dez. In http://dx.doi.org/10.1590/S0104-026X2005000300014. Acesso em 25.Jun.2018.

CAUSO, Roberto de Sousa. (2003) Fiçço científica, fantasia e horror no Brasil: 1875 a 1950. Belo Horizonte: Editora UFMG.

(Org.) (2007). Os melhores contos brasileiros de ficção cientifica. São Paulo: Devir.

(2013). Ondas nas Praias de um Mundo Sombrio: New Wave $e$ Cyberpunk no Brasil. (Tese - Doutorado em Estudos Linguísticos e Literários em Inglês), Faculdade de Filosofia, Letras e Ciências Humanas, Universidade de São Paulo.

(2014). "Os Pulps Brasileiros e o Estatuto do Escritor de Ficção de Gênero no Brasil". Revista Alambique, University of South Florida, 2. In http:// scholarcommons.usf.edu/alambique/vol2/iss1/5. Acesso em 03.Ago.2018. 
CLUTE, John. (2007). "Fantastika in the World Storm: a talk." In http://www. johnclute.co.uk/word/?p=15. Acesso em 25.Jun.2018.

DALCASTAGNÈ, Regina. (2005). "A personagem do romance brasileiro contemporâneo: 1990-2004". Estudos de Literatura Brasileira Contemporânea, [S.I.], (26), 13-71. In http://periodicos.unb.br/index.php/estudos/article/ view/2123/1687. Acesso em 03.Ago.2018.

FRASER, Nancy (2009). "O Feminismo, o capitalismo e a astúcia da história". Revista Mediações. Londrina, 14(2).

FURLANETTO, Elton (2010). Reificação e utopia na ficção científica norteamericana da Guerra Fria. (Dissertação - Mestrado em Estudos Linguísticos e Literários em Inglês), Faculdade de Filosofia, Letras e Ciências Humanas. Universidade de São Paulo. São Paulo.

GINWAY, Mary Elizabeth (2014). Ficção científica brasileira: mitos culturais e nacionalidade no país do futuro. São Paulo: Devir.

(2017). "A ficção científica no Brasil e no México: especulações preliminares". Com Ciência - Revista Eletrônica de Jornalismo Científico. Campinas. Dossiê 190: Ficção Científica. In http://www.comciencia.br/aficcao-cientifica-no-brasil-e-no-mexico-especulacoes-preliminares. Acesso em 23.Jan. 2018.

GOFFMAN, Erving (1974). Manicômios, prisões e conventos. São Paulo: Perspectiva.

HARVEY, David (2011). O enigma do capital e as crises do capitalismo. São Paulo: Boitempo.

HOBSBAWM, Eric (2013). Globalização, democracia e terrorismo. São Paulo: Companhia das Letras.

JAMESON, Fredric (1981). The Political Unconscious: Narrative as a Socially Symbolic Act. Cornell University Press.

(2005). Archaeologies of the Future: The Desire Called Utopia and Other Science Fictions. Londres, Nova York, Verso.

MATANGRANO, Bruno Anselmi e TAVARES, Enéias (2018). Fantástico brasileiro - o insólito literário do romantismo ao fantasismo. Curitiba: Arte e Letra.

MOYLAN, Tom (2016). Distopia: fragmentos de um céu límpido. Maceió: Edufal. 
PEREIRA, Fabiana da Camara Gonçalves (2005). Fantástica Margem: o cânone e a ficção científica brasileira. (Dissertação - Mestrado em Letras). Pontifícia Universidade Católica, Rio de Janeiro. In https://doi.org/10.17771/PUCRio. acad.6493. Acesso em 3.Ago.2018.

ROBERTS, Adam (2018). A verdadeira história da ficção científica: do preconceito à conquista das massas. Mário Molina (Trad.). São Paulo: Seoman.

RÜSCHE, Ana (2015). Utopia, feminismo e resignação. (Tese - Doutorado em Estudos Linguísticos e Literários em Inglês), Faculdade de Filosofia, Letras e Ciências Humanas, Universidade de São Paulo.

RUSS, Joanna (1995). To write like a woman: essays in feminism and science fiction. Bloomington: Indiana University Press.

SCHOLZ, Trebor (2016). Cooperativismo de plataforma: contestando a economia do compartilhamento corporativa. São Paulo: Fundação Rosa Luxemburgo; Editora Elefante; Autonomia Literária.

SILVA, Germano César (2011). "Piscina Livre", de André Carneiro: entre ícones e metamorfoses. (Dissertação - Mestrado em Teoria da Literatura), Faculdade de Letras, Universidade Federal de Pernambuco.

SYBYLLA, Lady (2017). Deixe as estrelas falarem. São Paulo: Dame Blanche.

SYBYLLA, Lady e VALEK, Aline (Orgs.) (2013). Universo desconstruído 1. São Paulo: Edição das autoras. In http://universodesconstruido.com Acesso em 25.Jun.18.

(2015). Universo desconstruído 2. São Paulo: Edição das autoras. In http://universodesconstruido.com. Acesso em 25.Jun.2018.

TAVARES, Bráulio (Org.) (2011). Páginas do futuro: contos brasileiros de ficção científica. Santo André: Casa da Palavra.

VALEK, Aline (2016). As águas-vivas não sabem de si. Rio de Janeiro: Rocco.

VAROUFAKIS, Yanis (2016). O Minotauro global: A verdadeira origem da crise financeira e o futuro da economia. São Paulo: Autonomia Literária. 